\title{
ANALYTICAL PREDICTION OF THERMAL PERFORMANCE OF HYPERVAPOTRON AND ITS APPLICATION TO ITER
}

\author{
by \\ C.B. BAXI and H. FALTER ${ }^{*}$
}

This is a preprint of a paper to be presented at the 17th Symposium on Fusion Technology, September 14-18, 1992, Rome, Italy, and to be printed in the Proceedings.

\author{
Work supported by \\ U.S. Department of Energy \\ Contract No. DE-AC03-89ER51114 \\ JET Joint Undertaking, Abingdon, Oxon, OX14 3EA, England.
}

*
GENERAL ATOMICS PROJECT 3466
SEPTEMBER 1992

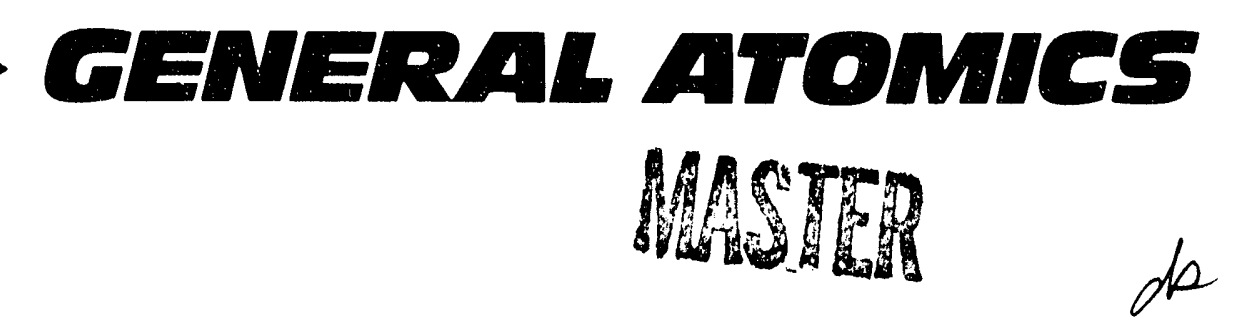




\title{
ANALYTICAL PREDICTION OF THERMAL PERFORMANCE OF HYPERVAPOTRON AND ITS APPLICATION TO ITER
}

\author{
C.B. BAXI and H. FALTER ${ }^{1}$ \\ General Atomics, P.O. Box 85608, San Diego, Califomia 92186-9784 \\ $1 \mathrm{JET}$ Joint Undertaking, Abingdon, Oxon, OX14 3EA, England
}

\begin{abstract}
A hypervapotron (HV) is a water cooled device made of high thermal conductivity material such as copper. A surface heat flux of up to $30 \mathrm{MW} / \mathrm{m}^{2}$ has been achieved in copper hypervapotrons cooled by water at a velocity of $10 \mathrm{~m} / \mathrm{s}$ and at a pressure of six bar.

Hypervapotrons have been used in the past as beam dumps at the Joint European Torus (JET). It is planned to use them for divertor cooling during Mark II upgrade of the JET. Although a large amount of experimental data has been collected on these devices, an analytical performance prediction has not been done before due to the complexity of the heat transfer mechanisms.

A method to analytically predict the thermal performance of the hypervapotron is described. The method uses a combination of a number of thermal hydraulic correlations and a finite element analysis. The analytical prediction shows an excellent agreement with experimental results over a wide range of velocities, pressures, subcooling, and geometries.

The method was used to predict the performance of hypervapotron made of beryllium. Merits for the use of hypervapotrons for Intermational Thermonuclear Experimental Reactor (ITER) and Tokamak Physics Experiment (TPX) are discussed.
\end{abstract}

\section{INTRODUCTION}

A hypervapotron (HV) consists of a finned surface made of high thermal conductivity material such as copper (Fig. 1). The coolant is a subcooled water, at a velocity of 8 to $12 \mathrm{~m} / \mathrm{s}$ and at a pressure of 4 to 10 bar. The flow is perpendicular to the fins. Miller (Ref. 1) has discussed the types of possible flows in such a geometry. Experiments (Refs. 2-3) have shown that an ideal geometry consists of fins with a height to pitch ratio of about 0.5 .
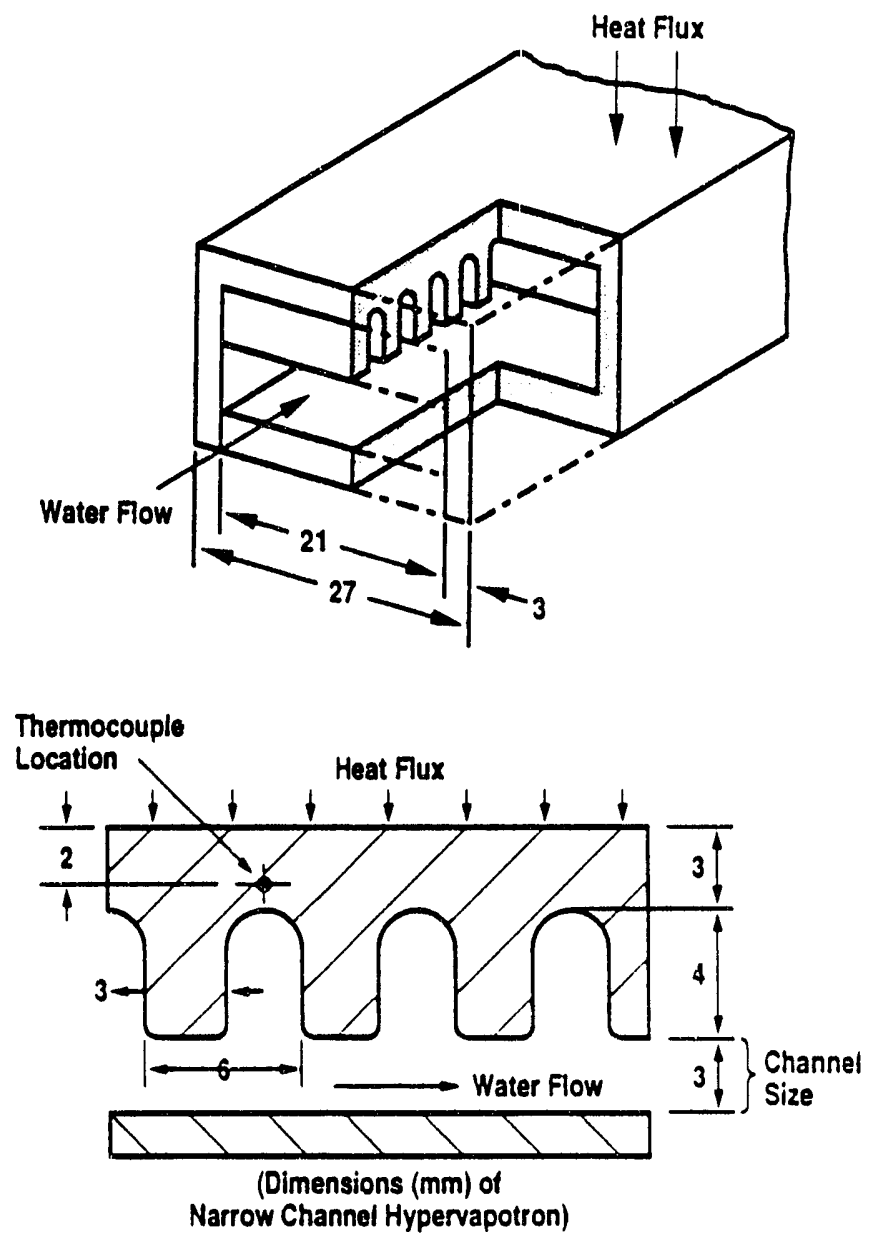

Fig. 1. Hypervapotron geometry. DImensions are in $\mathrm{mm}$ (typical fin height $=3$ to $6 \mathrm{~mm}$, thickness $=3 \mathrm{~mm}$, pitch $=6 \mathrm{~mm}$ ).

HVs have been used at JET as beam dumns to remove large heat fluxes under steady state conditions. 
Now plans are under way to install these devices with beryllium tiles brazed to the front surface as divertor targets. Extensive experiments have been carried out on HVs at the $10 \mathrm{MW}$ JET Neutral Beam Test Bed (Refs. 2-3). The test parameters cover a wide range of geometry, pressure, velocity and subcooling. Peak surface heat fluxes of about $30 \mathrm{MW} / \mathrm{m}^{2}$ have been obtained in these tests.

At low heat fluxes, the heat transfer in the $\mathrm{HV}$ is by forced convection. As the heat flux is increased, some of the heat transfer surface reaches the incipient boiling temperature of the coolant. With a further increase in power, critical heat flux conditions (maximum possible heit flux in nucleate boiling) are reached on part of the heat transfer surface.

A further increase in the surface heat flux could lead to melting or burnout of the device. The maximum heat flux and concomitant temperatures depend on the HV geometry, material of the HV, water pressure; velocity of flow, length of $\mathrm{HV}$, and coolant inlet temperature.

A method is presented to predict the thermal performance of HVs. This method uses a number of heat transfer correlations and finite element analysis. This method was used to predict the performance of an HV made of beryllium.

\section{ANALYSIS METHOD}

The heat transfer in an $\mathrm{HV}$ can be in three different regimes: (1) forced convection without boiling, (2) subcooled nucleate boiling and (3) citical heat flux condition. Due to a variation of temperature across the heat transfer surface, a combination of all these mechanisms can occur simultaneously in the HV. The following correlations were chosen for each of the regimes:

- Forced convection: Dittus-Boelter Correlation (Ref. 4)

- Nucleate boiling: Thom's correlation (Ref. 5)

- Critical Heat Flux: iviacbeth correlation for high mass flux warei flow (Refs. 6-10).

Heat transfer rates in the transition region between forced convection and nucleate boiling was calculated by the Rohsenow-Bergles method (Ref. 10).

The following two modifications were made to the above classical correlations:

1. The forced convection heat transfer coefficients calculated by the Dittus-Boelter correlation (Ref. 4) were increased by a factor of 1.35 to account for the recirculating flow (Ref. 1) which occurs in the channels formed by the fins. This factor was obtained by comparing calculated results with measured results at different flow velocities and geometries in the HV at low heat fluxes.

2. After the critical heat flux (CHF) was reached at a point on the heat transfer surface, it was assumed that the heat flux remained constant at the CHF value as the heat transfer surface temperature increased. This is justified because, unlike tlow through a tube, the vapor formed in the HV is swept away by vortices formed in the fin spacings. Details of the correlations are discussed in Ref. (11).

The above correlations were programmed into a computer code which created the input for the finite element code TOPAZ2D (Ref. 12) or COSMOS (Ref. 13). Figure 2 shows a typical variation of heat transfer coefficient as a function of local surface temperature in the cooling channel.

\subsection{Finite element model}

The finite element model for the TOPAZ2D code was of a half fin (Fig. 3). The incident heat flux, the coolant bulk temperature and heat transfer coefficients calculated from the above procedure were the boundary conditions. A steady-state calculation was performed. The aim was to calculate the temperature distribution in the HV.

\subsection{Comparison to experimental results}

Figure 4 shows the comparison of this analysis with experiments done at the JET Test Bed on a narrow channel ( $3 \mathrm{~mm}$ channel height) HV. As seen in Fig. 4(a), the heat transfer has three regions. In region 1, the heat transfer is by forced convection. In region 2, part of the heat transfer surface reaches incipient boiling temperature and hence the heat transfer coefficient is higher than the forced convection region, thus the slope $d T s / d q^{\prime \prime}$ is

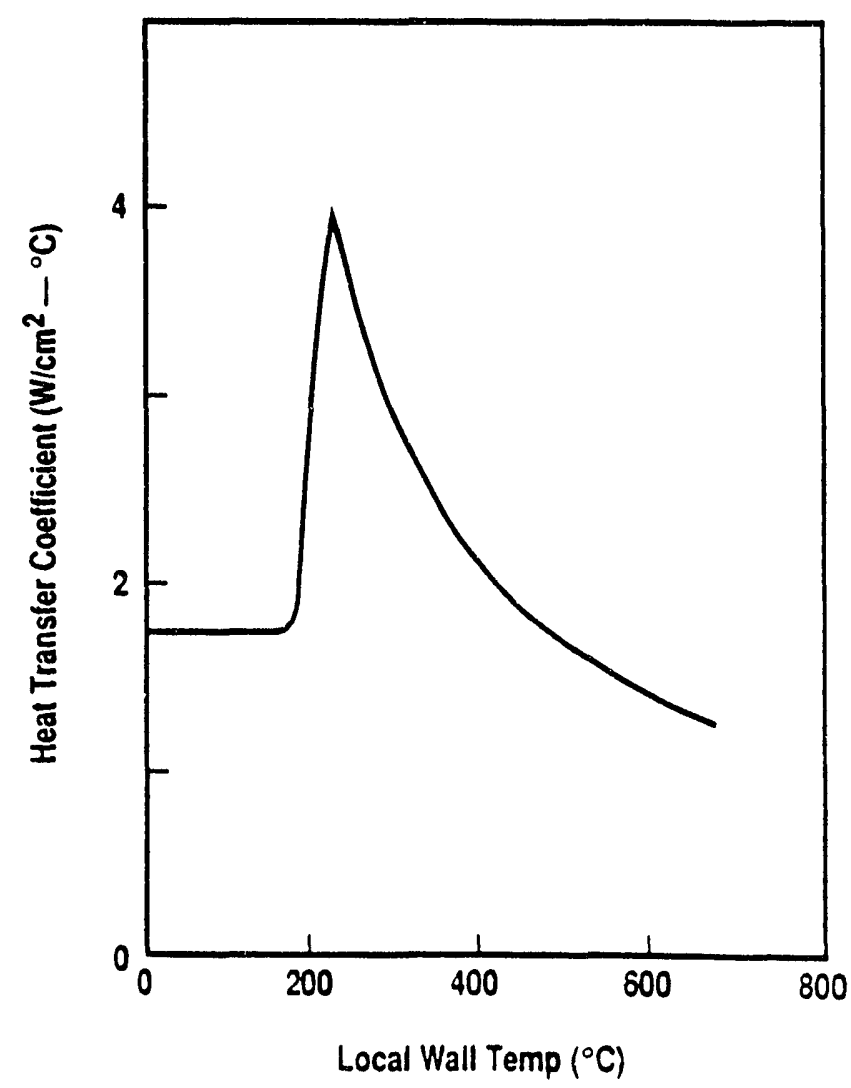

Fig. 2. Variation of heat transfer coefficient with surface temperature. 


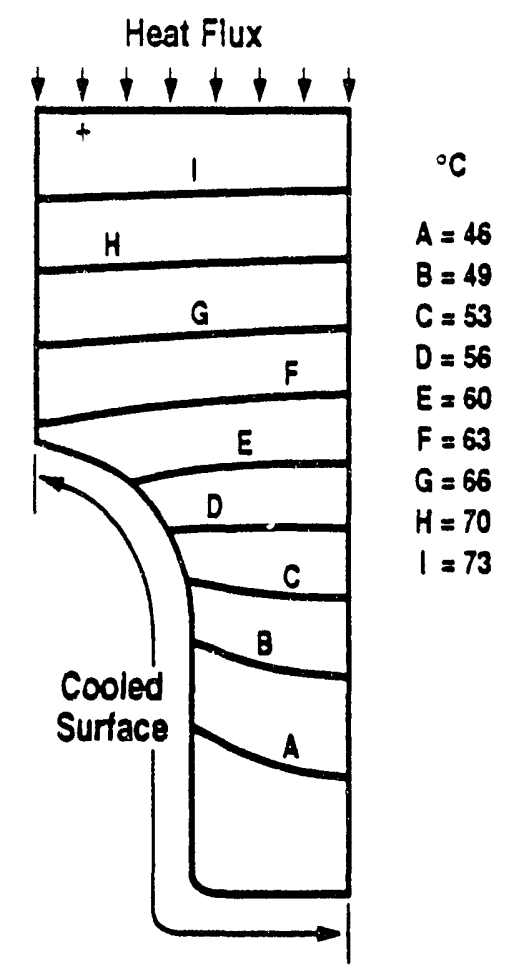

Isotherms for forced convection regime (heat flux = $2 \mathrm{MW} / \mathrm{m}^{2}$ ).

Fig. 3. Finite element model.

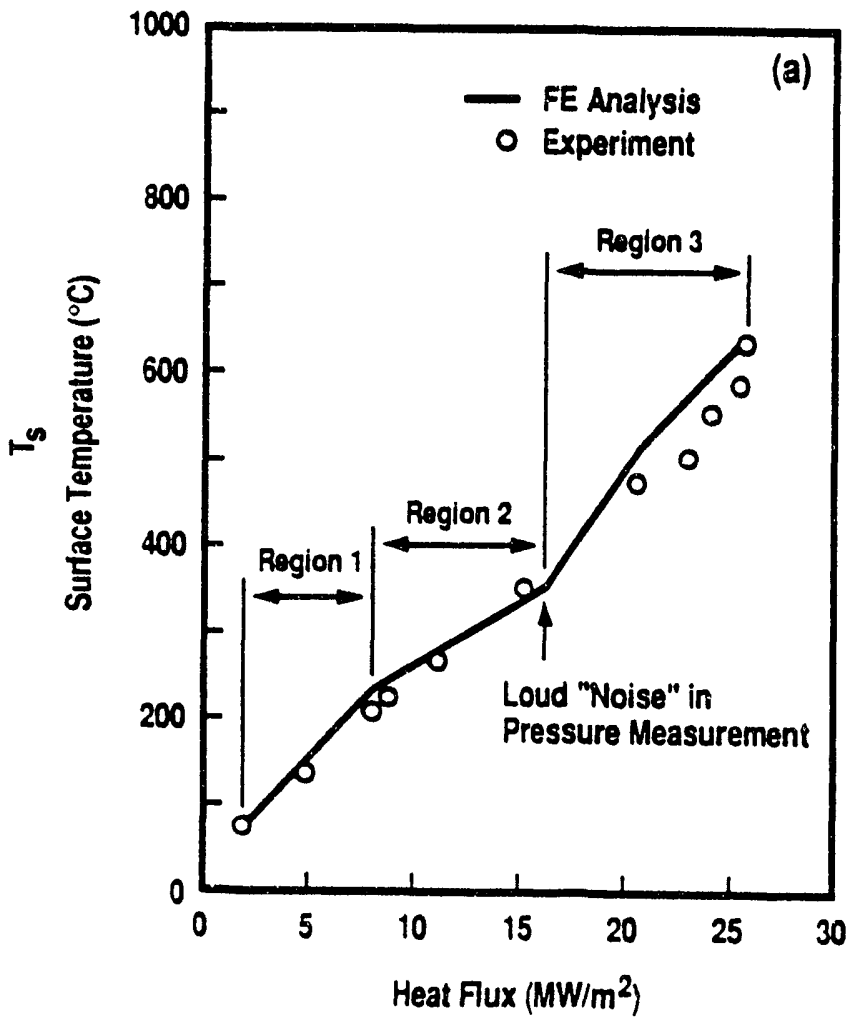

less than for the pure forced convection region. With further increase in the heat transfer surface temperature. some of the surface reaches the CHF condition. The heat transfer coefficient decreases with temperature once this condition is reached as seen from Fig. 2. Due to this, the surface temperature rapidly increases with heat flux increase. Raising the incident heat flux will finally make the local heat flux at all locations on the heat transfer surface greater than the critical heat flux and burnout occurs.

Figure 4 shows excellent agreement between this analysis and the experimental results. Analysis performed for a different geometry shows similar agreement (Ref. 11). This analysis covered a wide range of pressures, flow velocities and subcooling and two different geometries.

Another important observation in the experiment (Ref. 3) predicted by this analysis is the onset of large noise in the pressure signal at the outlet when the CHF condition is reached at the hottest heat transfer surface in the HV. This is the beginning of region 3 in Fig. 4 and coincides with the experimental observation.

\section{PERFORMANCE OF A BERYLLIUM HYPERVAPOTRON}

Tests at JET (Ref. 3) have shown that brazing of beryllium tiles to copper limits the performance of the $\mathrm{HV}$ to below about $16 \mathrm{MW} / \mathrm{m}^{2}$, due to difficulty in

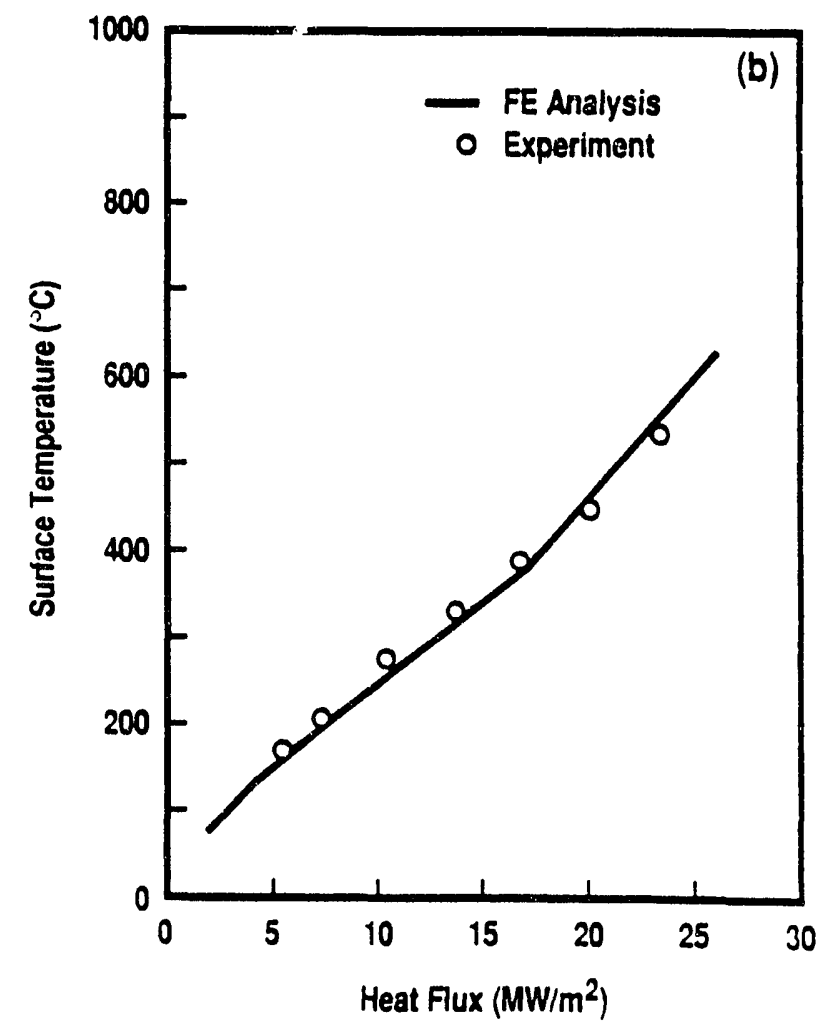

Fig. 4. Comparison with experiment. 
achieving a perfect braze between copper and beryllium. The braze could be eliminated if the entire HV diveror assembly could be made from beryllium.

The method presented above was used to predict the performance of an $\mathrm{HV}$ made of beryllium. Although beryllium is not compatible for direct contact with water, methods are under development (Ref. 14) to treat the flow channels with nitric acid, which allows water flow without chemical reaction between the treated surface and water. Another possibility is to use anodized beryllium. Figure 5 shows the predicted performance of an HV made from beryllium. Although the surface temperanure of a beryllium HV is higher than a copper HV, this presents an altemative to brazing the beryllium tiles to copper base. The surface temperatures shown in Fig. 5 for the beryllium HV are marginal. These could be reduced by optimizing the geometry and flow parameters. However, it appears that the use of beryllium HV technology may have to be limited to surface heat fluxes of less than $20 \mathrm{MW} / \mathrm{m}^{2}$.

\section{APPLICATION TO ITER AND TPX DIVERTORS}

The peak heat flux at the outer strike point of the divertor in ITER is expected to be $15 \mathrm{MW} / \mathrm{m}^{2}$. The reference design of the ITER divertor (Ref. 15) uses

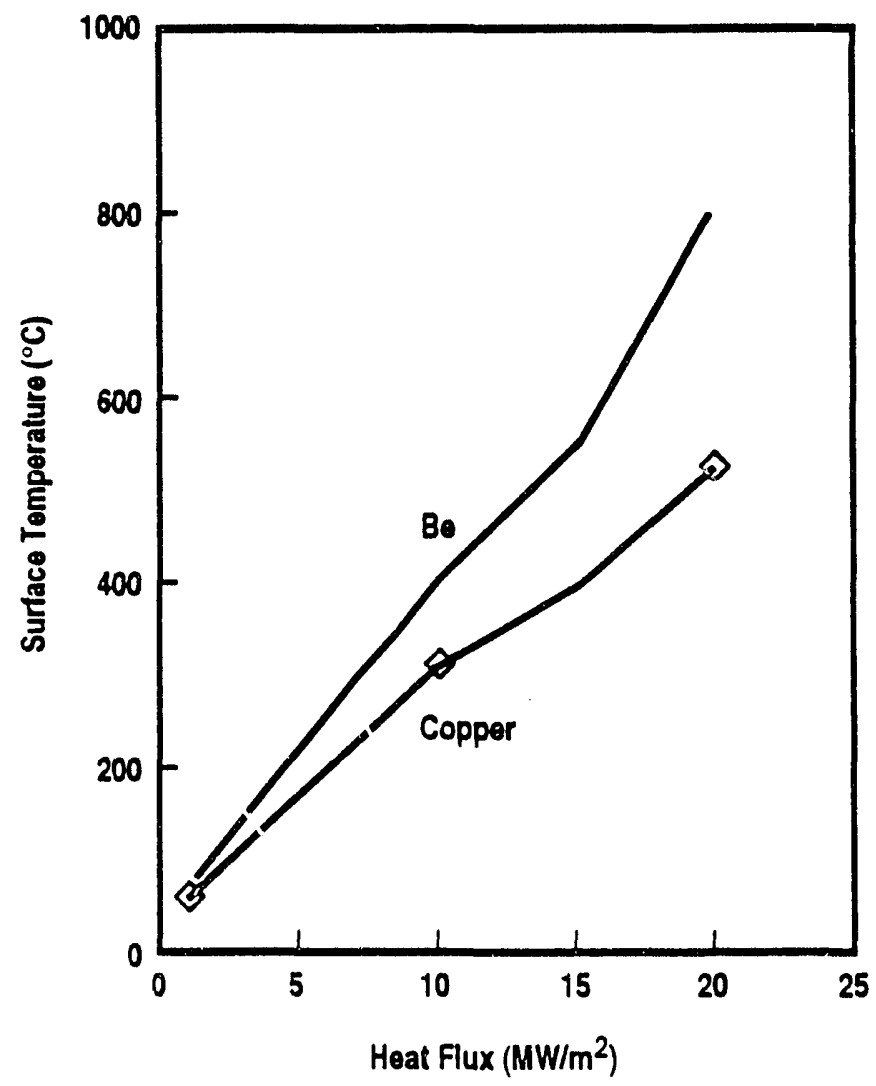

Fig. 5. Comparison of copper and beryllium hypervapotron. forced-convection, subcooled boiling, in tubes with twisted tape inserts. The peak heat flux in TPX is similar, and a design similar to ITER has been chosen for a TPX divertor.

Analytical results presented in this paper and the tests done at JET show that the copper HV is capable of steady-state heat flux removal in excess of $30 \mathrm{MW} / \mathrm{m}^{2}$. The HV should therefore be seriously considered as a heat removal device for the ITER divertor because it has following advantages over swirl tube cooling:

1. Breakage of twisted tape will degrade the expected performance of reference design. No such event can occur in a HV system

2. In the twisted tape design, each flow passage is a tube of $10-15 \mathrm{~mm}$ diameter. Flow blockage or flow reduction is highly probable in this small channel. By contrast, the HV uses wide channels.

3. The ITER design uses twisted tape inserts in circular flow channels. Since the divertor surface is flat. this increases the distance (and temperature difference) between the heat flux surface and the heat removal surface.

4. Side-by-side tests with HV and twisted tape tubes at JET (Ref. 3) have shown that there is no difference in thermal performance of these two concepts under identical thermal hydraulic conditions (water pressure, flow velocity and subcooling).

5. In swirl tube boiling heat transfer, the burn out occurs as soon as the CHF condition is reached at one point. In a $\mathrm{HV}$, the CHF condition has to be reached on all heat transfer surface before a runaway condition occurs. Thus the HV is a more robust design.

\section{DISCUSSION}

A method has been presented which predicts the thermal performance of both copper and beryllium hypervapotron. Although a HV made of beryllium will allow the divertor to be made without brazes, this analysis shows that such a divertor will be limited to heat fluxes below $20 \mathrm{MW} / \mathrm{m}^{2}$. Comparison of $\mathrm{HV}$ and twisted tape concepts shows that the HV is a better choice for ITER and TPX.

\section{ACKNOWLEDGMENT}

This work was supported by the U.S. Department of Energy under Contract No. DE-AC03-89ER51114.

\section{REFERENCES}

1. D.S. Miller, "Intemal Flow Systems," BHRA Fluid Engineering, 1978.

2 R. Tivey, et al., "Testing of Beam Stopping Elements Using Hypervapotron Cooling," Proc. of Symp.on Fusion Engineering, Monterey, Califomia, 1987. 
3. H. Falter, et al., "Thermal Test Results of the JET Divertor Plates," Presented at SPIE High Heat Flux Symposium. San Diego. California. 1992.

4. "Handbook of Heat Transfer Fundamentals," W.M. Rohsenow, et al., editors McGraw-Hill Book Company, New York, 1983.

5. A.E. Bergles and W.M. Rosenhow, "The Determination of Forced Convection Surface Boiling Heat Transfer," paper 63-HT-22. Presented at the 6th National Heat Transfer Conference of the ASME-AIChE, Boston 1963.

6. J.R.S. Thom, W.M. Walker, T A. Fallon, and G.F.S. Reising, "Boiling in Subcooled Water During Flow in Tubes and Annuli," in Proc. Inst. Mech. Eng. 3C (1965) 180.

7. B. Thompson and R.V. Macbeth, "Boiling Water Heat Transfer - Burnout in Uniformly Heated Round Tubes: A Compilation of World Data With Accurate Correlations," AEEW-R (1964) 356.
8. R.V. Macbeth, "Bum-Out Analysis: Part 3. The Low Velocity Bumout Regime," AEEW-R (1963) 222.

9. J.G. Collier, "Convective Boiling and Condensation," McGraw-Hill, New York.

10. A.E. Bergles and W.M. Rohsenow, J. Heat Transfer 86 (1964) 365 .

11. C.B. Baxi and H. Falter, "A Model for Analytical Performance Prediction of Hypervapotron," to be presented at the NURETH-5. Fifth Intemational Topical Meeting on Nuclear Reactor Thermal Hydraulics, Salt Lake City, Utah, 1992.

12. A.B. Shapiro, "TOPAZ - A Finite Element Heat Conduction Code," UCID-20045, March 1984.

13. "COSMOS, A Finite Element Analysis Code," Structural Research, Santa Monica, Califomia code.

14. Private Communication with P. Rebeut, May 1992.

15. U.S. ITER Team, "U.S. Contribution to the ITER Plasma Facing Components Engineering Homework Task," ITER TN-PC-1-9-U-1 (1989). 

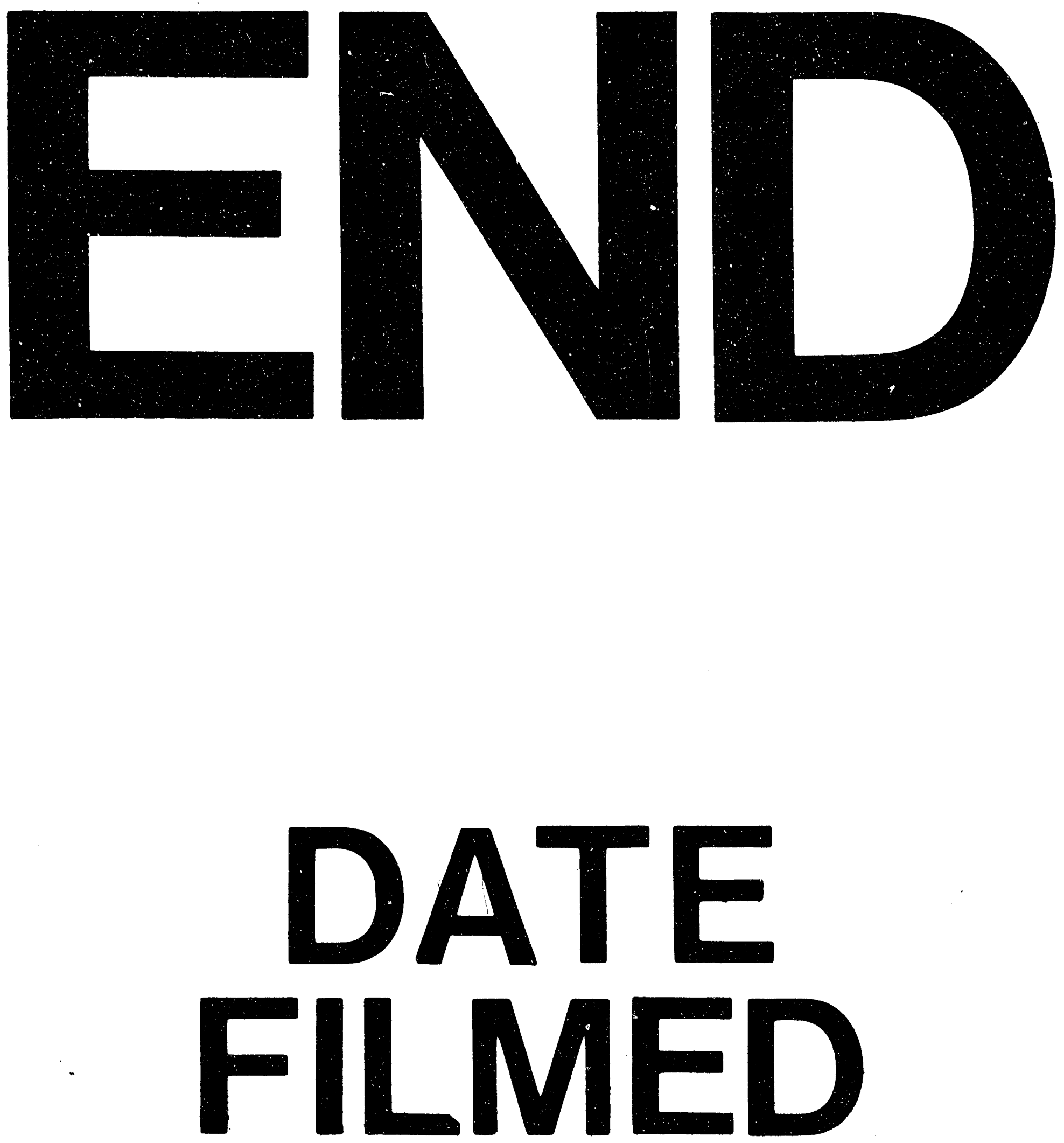

1

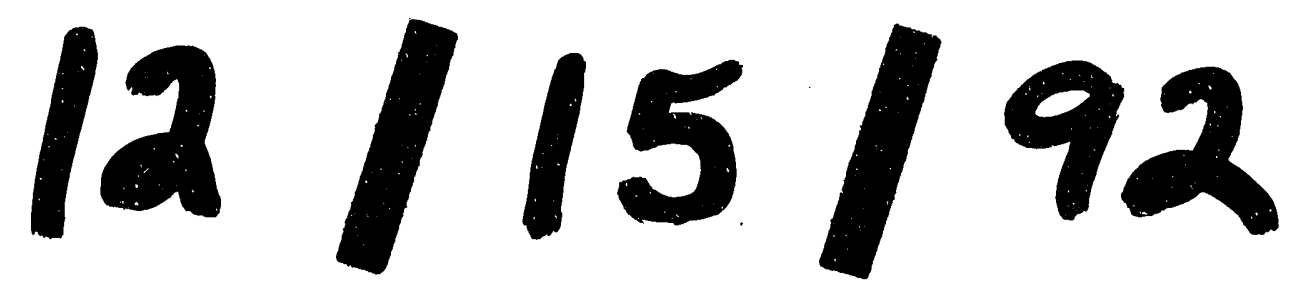




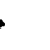

